\title{
New trends in training nuclear power plant employees: probabilistic safety analysis
}

\author{
Cristian TUDORAN \\ University of Bucharest, Bucharest, Romania \\ ct@cristiantudoran.ro
}

\begin{abstract}
In the last four decades, as the nuclear industry grew and got mature, the importance of adequate risk evaluating tools became decisive. Therefore, the Probabilistic Risk Assessment (also known as Probabilistic Safety Analysis) became a cornerstone of the decisions in such high energy and high-risk industry. PSA has an internationally recognised standard, and it is supported by a group of highly trained experts, (no more than a few hundred worldwide). This work can be used as a guide for the improving the required individual and teamwork skills needed in a Probabilistic Safety Analysis - PSA Team. The necessity of such a moment in a PSA Training was imagined by Dan Serbanescu, doctor in science, nuclear energy expert, risk and safety analyst, in May 2017. After few discussions and according to recognised international standards (Probabilistic Risk Assessment procedures guide, 1983), a first time delivery was possible in the PSA Training delivered in Centrala Nuclearoelectrica Cernavoda / Nuclear Power Plant Cernavoda (2017).This article presents a systematic approach for team improvement skills, consisting of the observation, presentation of the skills required, the skills practised in the proposed exercises, the techniques used during this module (coaching included), and results. The Purpose of the newly proposed combination of training and coaching methods with the specific traditional one oriented mainly to the technical and procedural skills is to raise participants' awareness about how soft-skills can be used in the PSA Teamwork. As Nuclear Power Plant can be easily compared with a complex organisation, soft skills are vital to be developed within the teams. PSA is becoming more required not only in nuclear but also in the aerospace industry (it was adopted by NASA - National Aeronautics and Space Administration for all future space program and by some hazardous chemical industries, as also stated in international documents (of the European Commission for instance).
\end{abstract}

Keywords: probabilistic safety analysis, training, group facilitation, managerial skills.

\section{Introduction}

In the last four decades, as the nuclear industry grew and got mature, the importance of adequate risk evaluating tools became decisive. Therefore, the Probabilistic Risk Assessment (also known as Probabilistic Safety Analysis) became a cornerstone of the decisions in such high energy and high-risk industry.

PSA has an internationally recognised standard, and it is supported by a group of highly trained experts, "No more than a few hundred worldwide" according to Dan Serbanescu, a nuclear energy expert.

PSA is becoming more required not only in nuclear but also in the aerospace industry (it was adopted by National Aeronautics and Space Administration - NASA for all future space program and by some hazardous chemical industries, as also stated in international documents (of the International Atomic Energy Agency - IAEA European Commission for instance).

Up to the present, the PSA training has been developed as a highly technical learning approach, solely addressed to nuclear energy professionals who could rapidly process an impressive amount of analytical, technical data and procedures.

The origins of this work descend from an observation of Dan Serbanescu, nuclear energy expert, risk and safety analyst, who understood, from his extended on the ground experience on the issue, that the activity of a complex PSA team can be improved by 
paying attention to their people. Having developed this idea together, we noticed that, until 2017, there had been no PSA Training Programmes in Romania to include coaching/facilitation and to holistically approach the training process of these experts: technical and human component as part of the same programme syllabus. After few discussions and according to recognised international standards (as Probabilistic Risk Assessments - PRA procedures guide, that is also mentioned as NUREG 2300 in literature), a first time delivery was possible in the PSA Training delivered in Centrala Nuclearoelectrica Cernavoda (CNE) / Nuclear Power Plant (NPP) Cernavoda (2017).

Speciality literature does not make any references about PSA programmes that combine technical training with other methods, such as facilitation, coaching or training to instruct nuclear energy risk analysts.

This case study is a unique performance in PSA training activity as, for the first time, the activity carried out at NPP Cernavoda for two weeks, during June and August 2017, included coaching/facilitation techniques for nuclear energy risk experts from different departments, sometimes divergent as areas of interest.

The question raised by this case study is: can coaching/facilitation improve the PSA training participants' performance?

This work can be used as a guide for the required skills to be present in a Probabilistic Safety Analysis - PSA Team. This article consists of the observation, presentation of the skills required, the skills practised in the proposed exercises, the techniques used during this module (coaching included), and results.

The Purpose is to raise participants' awareness about how soft-skills can be used in the PSA Teamwork.

As Nuclear Power Plant - NPP can be easily compared with a complex organisation, and soft skills are vital to be developed within the teams.

\section{Literature review}

\section{General Description of a Probabilistic Safety Analysis - PSA Project}

Let's design an example of how the Probabilistic Safety Analysis - PSA Team must deliver to the Beneficiary a document that contains a proper solution, and this solution should have to be put into practice immediately.

The full scope PSA work has the following characteristics: it has a goal, it includes about 15 tasks (for PSA level 1), it lasts for at least 12 months, it has a budget, and it is a predefined team.

A PSA Team should have at least ten members. Ideally, the team should have 18 members.

The team is divided into sub-teams. Each member may be the leader for a task, while in another task can be a sub-team member. This approach is recommended as it is supposed to homogenise the team. The whole team is divided into at least five subteams.

\section{The PSA Team Mission}

To generate (as accurate as possible) answers to the multiple demands of an NPP. NPP is seen/qualified as a complex system.

\section{The PSA Team Objective}

To provide a solution, at least one, taking into consideration all the possible issues that can occur within a specific time frame. 
The identified solution needs to be: specific, measurable, agreed, realistic, and time-bound. It needs new thinking patterns (Bratianu, 2007, 2009) and a good understanding of decision-making under uncertainty conditions (Bratianu and Bolisani, 2015).

Taking into consideration all from the above, the PSA Team Members need to cooperate during the whole process. It is a challenging process as the team members are people with different specialisations and background, experienced in their field, and at different ages - from different generations.

\section{Nuclear Power Plant Trainings - A Necessity}

International Atomic Energy Agency (IAEA) is fully committed to the training of all the nuclear employees involved in nuclear activities. In this respect, IAEA had a free access site (e-learning) with dedicated modules to all the entities that can be involved Nuclear Power Programmes and specific peer review services for PSA Projects. Module 6 is "Systematic Approach to Training (SAT)", a module that "is internationally recognized as a key tool for ensuring the competency of all Nuclear Power Programme personnel" (IAEA, 2017), including the training for NPPs' employees.

\section{References in literature review regarding PSA Training}

NUREG 2300 (PRA procedures guide) and documents elaborated by IAEA regarding PSA Training. All documents referred to high technical aspects. There is no document to refer to team (not only technical aspects) facilitation/coaching techniques used in PSA Training Programmes.

PhD Dan Serbanescu, private communication: "As a PSA expert, I have encountered only technical elements in training highly complex teams. My expertise in PSA is large: from a team member and task manager, PSA Project Manager to Internal and External Supervisor for PSA Projects."

In "Selected topics in Risk Analyses for some Energy Systems" Serbanescu enumerates both science myths and risk analysis myths (2015, p. 141).

Myths on risk analyses:

MyR1 - "Risk" must have a single, well-defined meaning.

MyR2 - The severity of risks should be judged according to probabilityweighted averages of the severity of their outcomes.

MyR3 - Decisions on risks should be made by weighing total risks against total benefits.

MyR4 - Decisions on risks should be taken by experts rather than by laymen.

MyR5 - Risk-reducing measures in all different sectors of society should be decided according to the same standards.

MyR6 - Risk assessments should be based only on well-established scientific facts.

MyR7 - If there is a serious risk, the scientist will find it if they look for it."

Obvious the human factor is present in risk analysis, in Myths 1,3,4,5, and 7 . Therefore, it should be fully integrated into PSA Training.

I found that the term HOF, meaning Human Organisational Factor, which is taken from the literature, is found in this understanding in the Dan Serbanescu's work (2016, p.2), which presents the impact that the human factor may have on the risk assessment of nuclear power plants. 
- "The role of HOF in plant safety and low risks is increasing for higher levels of Defence in Depth. HOF is dominant for accident management and emergency levels.

- The evaluation of the impact on risk of HOF for these levels is essential."

\section{Definition of Basic Concepts}

Training means: teaching somebody else any knowledge and/or skill, hoping that the other ones will get a useful competence. It is often intended to increase capability, capacity, productivity or performance.

Facilitation means: when working with a group of people or a team to create learning opportunities; to create a learning environment; to challenge thinking to develop the understanding; to encourage participants to share knowledge; to focus on module's objective; to build consensus; to build agreement; to focus on learning/learner.

Coaching means: unleashing someone's potential by support or challenge, without advice even if it is asked; raising as well the awareness of the client using questions, exercises and observations, as the wisdom of them both (n.b. client and coach) to act in the future.

Group Coaching means: the use of coaching technique to work with a group of people employed in different entities of the same organisation, and who have no formal work interaction on a daily basis (Ridler \& Co, 2016).

Team Coaching means: a team of coaches using the individual coaching, sub-team coaching, group facilitation, team building and organisational development with the aim of reaching the Team's Goal altogether (Leary-Joyce, 2014).

The beforehand concepts have been presented in the light of my expertise and experience in the field, more than 22 years. We have started from the conclusion that different authors defined each of them according to their knowledge and interests in the respective field. Therefore, we do not have a unitary approach that could clarify all similarities and differences between these intervention methods within organisations.

In PSA Training speciality literature there is no reference to the usage of coaching and/or facilitation of training nuclear energy risk and safety analysts.

This work can be used as a guide for the improving the required individual and teamwork skills needed in a Probabilistic Safety Assessment Team - PSA Team.

\section{Methodology}

The research was carried out within the PSA Training project at Centrala Nuclearoelectrica Cernavoda (CNE Cernavoda) / Nuclear Power Plant Cernavoda (NPP Cernavoda) in 2017.

The PSA Training Project was coordinated by Dan Serbanescu, PhD, risk and safety analyst, an expert in nuclear energy.

The project lasted for two weeks (one week in June and one week in August), and it was structured in two modules.

The first module included the "classical" PSA on the job training approach, based on technical elements, risk analysis, mathematical data, statistics and it was delivered by Dan Serbanescu, the Project Manager.

The second module - PSA Team Project - was carried out on August $21^{\text {st }}-25^{\text {th }}$, 2017. It approached both aspects of PSA team training: highly technical elements and facilitation techniques.

My contribution to this study: to apply group facilitation techniques during the second module (the first four days out of 5) simultaneously with the technical training \& 
to study their effects upon the participants' performances, responses and involvement as a team in the PSA Training.

The target group was made of ten experts in nuclear risk and safety, who have attended both modules. All participants attended all ten training days. Analysing the structure of the target group, I have noticed a particular feature. The group was apparently homogenous from the technical point of view, but they came from different departments and organisations with different areas of interest and natural asperities. This particular, unique feature could influence the group dynamics and the work during the training.

Study methods approached

I have applied the following study protocol for the PSA Team Projects:

1. At the end of Module 1 (exclusively technical), the Project Manager requested feedback from the participants.

2. The Project Manager filled in an assessment form for the first PSA training week.

3. Day one and two during Module 2: direct observation of participants and Project Manager's interview. All results were recorded in the Observation Form.

4. In the Facilitation Module, I used five exercises carried out by the model: briefing, practice, and debriefing.

5. At the end of Module 2, the Project Manager requested another feedback from the participants.

6. At the end of Module 2, the Project Manager filled in an assessment form.

\section{Results and discussions}

Outcomes after the first PSA Training week, provided by the Project Manager:

- interaction among Task Teams was low

- transmission of information between sub-teams was lapidary

- the group dynamic was almost non-existent

- participants preferred to shut up instead of providing feedback

Taking into considerations these outcomes, together with the Project Manager, we chose to build a module to accomplish the features below.

\section{Module's Scope}

This module was designed to equip the participants in the PSA Training with the skills required for improving their collaboration processes. The module was specifically designed for the teams involved in solving PSA themes.

\section{Module's Mission}

To equip PSA Team Members with the skills required for an active relationship in a team.

\section{Module's Purpose}

To raise participants' awareness about how soft-skills can be used in the PSA Teamwork. Following the process of delivering the PSA Training, I understood that participants are highly specialised in their field of activity. At the same time, I noticed that they do not pay attention to the details that are recommended for the productive interactions.

Here are the outcomes of my observation during the Team Presentations that support my statement from above: lack of notions of public presentation; exceeding the presentation time; abrupt language of disagreement; the manner of asking questions seemed like a hindrance to team communication; speaking over the speaker, without 
listening; ignoring the audience by the presenter during the delivery of the presentation (the members of one of the teams stood with their back turned to the audience); lack of harmonization of the opinions of the two team members before the delivery of the presentation; the inability of the presenters to involve the audience while presenting (the other sub-teams were focused on their task instead to attend the presentation) only one team succeeded in involving the audience; three sub-teams included excessive information, some not relevant to the audience; fear of being judged wrong (as they would not know all the necessary information about the topic).

I have considered the following:

- the target-group includes highly specialised professionals in nuclear plant safety;

- the group was apparently homogeneous;

- the approach of the project is Teamwork in the network;

- participants were lacked managerial competencies.

I have chosen to focus my intervention on the managerial issues that are also recommended for teamwork, to improve group dynamics too.

What does a manager do?

"Most writers on management in this part of the twenty-first century would agree that it is the planning, organising, leading and controlling of human and other resources to achieve organisational goals efficiently and effectively." (OpenLearn, 2017).

I considered that it is vital that participants to understand that in their role as manager and a task leader they will be assessed on results and on the level of competence they used in reaching those results.

"Competence is about knowledge and skills - what people need to know and be able to do to carry out their work well." (Armstrong, 2017)

Once the knowledge is shared and the skill is practised, we can imagine and hope that the managerial competence will become a way of future managerial behaviour.

My option for this group was to use the facilitation technique.

I took this decision based on the following facts.

During the facilitation process, the facilitator should encourage the learner: to challenge their attitude; to meet their needs; to support to understand the new/improved skill; to develop their confidence/self-esteem; to test the new approach on his/her behaviour; to internalise the new behaviour.

During the facilitation process, one should be aware of: non-judgemental; not to blame; not to hurt.

How can the facilitation technique influence the PSA Training Teamwork?

The advantages of using the Facilitation approach: no right or wrong answer; participants are free to take what each of them needs; support the openness through discussion.

Facilitation approach: encourages the human openness of participants; participants do not feel assessed; participants feel free to focus on whatever they consider being a matter of interest for each of them.

Taking into consideration the above mentioned, I chose to focus my intervention on Managerial Competencies that influence in teamwork too.

The approach led to practical situational exercises.

The combination of exercises is original. I have adapted them to the participants' needs. 
The managerial competences described by Michael Armstrong (2017, p.13) are found in various skills combinations in each of the exercises proposed in the facilitation module of PSA Training. (See Table 1)

Table 1. Distribution of Practiced Managerial Skills in Facilitation Module of the PSA Training

\begin{tabular}{|c|c|c|c|c|}
\hline & $\begin{array}{l}\text { People } \\
\text { Management }\end{array}$ & $\begin{array}{l}\text { Management } \\
\text { Skills }\end{array}$ & Personal Skills & $\begin{array}{l}\text { Developing } \\
\text { People }\end{array}$ \\
\hline $1^{\text {st }}$ exercise & & To be creative & $\begin{array}{l}\text { To be decisive } \\
\text { To listen } \\
\text { To make a solid } \\
\text { argument }\end{array}$ & $\begin{array}{l}\text { To relate to each } \\
\text { other }\end{array}$ \\
\hline $2^{\text {nd }}$ exercise & To treat people right & $\begin{array}{l}\text { To be an active } \\
\text { member of a } \\
\text { meeting } \\
\text { To be creative } \\
\text { To manage } \\
\text { conflict } \\
\text { To manage stress } \\
\text { To manage time } \\
\text { To negotiate } \\
\text { To plan and } \\
\text { prioritise }\end{array}$ & $\begin{array}{l}\text { To be assertive } \\
\text { To be decisive } \\
\text { To communicate } \\
\text { To listen } \\
\text { To make a solid } \\
\text { argument } \\
\text { To make effective } \\
\text { presentations }\end{array}$ & $\begin{array}{l}\text { To relate to each } \\
\text { other }\end{array}$ \\
\hline $3^{\text {rd }}$ exercise & To provide feedback & & $\begin{array}{l}\text { To make effective } \\
\text { presentations }\end{array}$ & $\begin{array}{l}\text { To relate to each } \\
\text { other }\end{array}$ \\
\hline $4^{\text {th }}$ exercise & $\begin{array}{l}\text { To be an engaging } \\
\text { manager } \\
\text { To provide feedback }\end{array}$ & $\begin{array}{l}\text { To manage stress } \\
\text { To manage time }\end{array}$ & $\begin{array}{l}\text { To listen } \\
\text { To make effective } \\
\text { presentations }\end{array}$ & \\
\hline $5^{\text {th }}$ exercise & To provide feedback & $\begin{array}{l}\text { To manage stress } \\
\text { To plan and } \\
\text { prioritise }\end{array}$ & $\begin{array}{l}\text { To assess own } \\
\text { performance } \\
\text { To communicate } \\
\text { To listen } \\
\text { To question } \\
\text { effectively } \\
\text { To make effective } \\
\text { presentations }\end{array}$ & \\
\hline
\end{tabular}

Source: Author's own research results

\section{Skills areas}

People Management Skills - It is easy to say that people are the most important asset of an organisation. People management practices can have positive and profitable outcomes in an organisation, and we can assume that the PSA Team has the characteristics of an organisation.

People Management used in the Facilitation Module are: Being an engaging manager, Providing feedback, and Treating people right.

Management Skills - The concept sounds so pompous that it could impress. In fact, it includes actions that a manager practices every day, the most of them.

Management Skills used in the Facilitation Module are: Being an active member of a meeting, Managing conflict, Managing stress, Managing time, Negotiating, Organizing, and Planning and prioritising.

Personal Skills - These can also be called "The Skills You Need". Sometimes they can be divided into soft skills and hard skills. Soft Skills would refer to the skills we need in everyday life, and Hard Skills would refer to those that can make someone hireable. 
Personal Skills used in the Facilitation Module are: Assessing own performance, Being assertive, Being creative, Being decisive, Communicating, Effective questioning, Listening, Making effective presentations, and Making a solid argument.

Developing People Skills - Usually, we are tempted to assume that it is the task of a trainer, mentor or coach. Managers, even if gone through such programs, have not been trained to do such specific interventions. However, there are ways that each employee, including managers, can contribute to the development of another.

Developing People Skill used in the Facilitation Module is: Relating to each other.

Exercises were compound, and the members of the PSA Team had many challenges; they were invited to work in random sub-teams and then to deliver the final result as a team.

How the participants reacted - personal observation, (Table 2).

Table 2. Participants' Reactions \& Behaviour during the Stages of the Module

\begin{tabular}{|l|l|}
\hline Stages of The Module & Participants' reactions/behaviour \\
\hline Before starting the workshop & $\begin{array}{l}\text { They were intrigued } \\
\text { During the break, they asked questions about an assessment (for } \\
\text { sure there was a misunderstanding) } \\
\text { They were late }\end{array}$ \\
\hline During the workshop & $\begin{array}{l}\text { After the first exercise - they become attentive } \\
\text { There were keen to respect the indications received } \\
\text { Some of them have become more and more attentive to the words } \\
\text { used by the facilitator for the task instructions } \\
\text { They easily accepted the exercises' challenges }\end{array}$ \\
\hline After the workshop & $\begin{array}{l}\text { They were keen to share their discoveries } \\
\text { They were enthusiasts about future developments of the training of } \\
\text { this module } \\
\text { A high level of energy } \\
\text { Availability for person-to-person interaction }\end{array}$ \\
\hline
\end{tabular}

Source: Author's own research results

All participants were open and eager to give feedback, expressing their impressions. Some of them are: "Many learnings in an attractive manner.", "Good exercises.", "You managed to shake us!"

Feedback provided by the Project Manager - private communication:

"Following PSA Training Course developed at CNE Cernavoda I noticed that participants unblocked their psychological, behavioural and mental level to complete the task given. Apparently, the participants gave the impression they understood their task, but they proved to focus on them poorly."

\section{My feedback and Conclusions:}

$\checkmark$ Some participants internalised some of the recommended behaviours

$\checkmark$ Fear of failure may generate a need for developing Habits of Success

$\checkmark$ Participants need to be trained in the decision-making process

$\checkmark$ Participants need to be trained in managerial soft-skills with the aim of increasing personal confidence

$\checkmark$ A facilitation module may help participants get a bigger picture and understanding of the whole event

$\checkmark$ Training will increase the awareness of the importance of the decision-making process

$\checkmark$ Highly specialised people may lack managerial soft-skills 


\section{Conclusion}

The project demonstrates that the use of facilitation techniques during highly specialised training, especially in high-risk industries, encourages human openness which helps participants feel unblocked and improves group dynamics. Facilitation techniques ultimately help participants achieve the project goals.

PICBE | 991

Because the participants do not feel assessed, they feel free to focus on whatever consider being a matter of interest for each of them and this can lead to the improved performance of the training outcome.

Increasing participants' communication availability leads to more efficient information transmission between sub-teams within the project, improving PSA Training final results.

Considering that facilitation and coaching focus on participants' learning, introducing specific coaching exercises could increase the effectiveness of the PSA Project in the future.

This study is the first of its kind in a PSA Training Project. By using facilitation as a distinctive part of a PSA Training offering, it provides a holistic approach to the training process of these experts, encompassing both technical and soft skills.

\section{References}

Armstrong, M. (2017). How to be an Even Better Manager: a complete a-z of proven techniques and essentials skills. 10th ed. New York: Kogan Page.

Bratianu, C. (2007). Thinking patterns and knowledge dynamics. In Martins, B. and Remenyi, D. (Eds.). Proceedings of the $8^{\text {th }}$ European Conference on Knowledge Management, 6-7 September 2007. Consorci Escola Industrial de Barcelona, Barcelona, Spain (pp. 152-157). Reading: Academic Conferences.

Bratianu, C. (2009). The frontier of linearity in the intellectual capital metaphor. In Stam, C. and Andriessen, D. (Eds.). Proceedings of the European Conference on Intellectual Capital (pp.97-103). Inholland University of Applied Sciences, Haarlem, The Netherlands, 28-29 April 2009. Reading: Academic Conferences and Publishing International.

Bratianu, C. and Bolisani, E. (2015). Knowledge strategies: an integrated approach for managing uncertainty. In Massaro, M. and Garlatti, A. (Eds.). Proceedings of the $16^{\text {th }}$ European Conference on Knowledge Management, University of Udine, Italy, 3-4 September 2015 (pp. 169-177). Reading: Academic Conferences and Publishing International.

(IAEA), I. (2017). E-learning - Nuclear Power - IAEA. [online] Iaea.org

Leary-Joyce, J. (2014). "International Systemic Team Coaching Certificate" Programme.

PRA procedures guide. (1983). Washington, D.C.: Office of Nuclear Regulatory Research, U.S. Nuclear Regulatory Commission.

OpenLearn. (2017). Managing and managing people. [online] Available at: http://www.open.edu/openlearn/money-management/management/leadershipand-management/managing-and-managing-people/content-section-0 [Accessed 29 Dec. 2017].

Ridler \& Co (2016). STRATEGIC TRENDS IN THE USE OF COACHING. 6th Ridler Report. London: Ridler \& Co.

Serbanescu, D. (2015). Selected topics in Risk Analyses for some Energy Systems.

Saarbrücken: LAP LAMBERT Academic Publishing.

Serbanescu, D. (2016). Risks and Human Organizational Factors. 